\title{
Office-based vs. operating room-performed laryngopharyngeal surgery: a review of cost differences
}

\author{
Anouk S. Schimberg ${ }^{1}\left(\mathbb{D} \cdot\right.$ David J. Wellenstein ${ }^{1}$. Eline M. van den Broek ${ }^{2}$. Jimmie Honings ${ }^{1}$. \\ Frank J. A. van den Hoogen ${ }^{1} \cdot$ Henri A. M. Marres ${ }^{1} \cdot$ Robert P. Takes $^{1} \cdot$ Guido B. van den Broek ${ }^{1}$
}

Received: 27 June 2019 / Accepted: 24 August 2019 / Published online: 5 September 2019

(c) The Author(s) 2019

\begin{abstract}
Purpose Office-based transnasal flexible endoscopic surgery under topical anesthesia has recently been developed as an alternative for transoral laryngopharyngeal surgery under general anesthesia. The aim of this study was to evaluate differences in health care costs between the two surgical settings.

Methods PubMed, EMBASE and Cochrane Library were searched for studies reporting on costs of laryngopharyngeal procedures that could either be performed in the office or operating room (i.e., laser surgery, biopsies, vocal fold injection, or hypopharyngeal or esophageal dilation). Quality assessment of the included references was performed.

Results Of 2953 identified studies, 13 were included. Quality assessment revealed that methodology differed significantly among the included studies. All studies reported lower costs for procedures performed in the office compared to those performed in the operating room. The variation within reported hospital and physician charges was substantial.

Conclusion Office-based laryngopharyngeal procedures under topical anesthesia result in lower costs compared to similar procedures performed under general anesthesia.
\end{abstract}

Keywords Office-based $\cdot$ Topical anesthesia $\cdot$ Operating room $\cdot$ Pharynx surgery $\cdot$ Larynx surgery $\cdot$ Costs $\cdot$ Costeffectiveness

\section{Introduction}

Most patients with lesions in the pharynx or larynx are traditionally treated in the operating room (OR) under general anesthesia. Since flexible endoscopes with distal chip technology have been introduced, the imaging quality improved significantly compared to fiber optic images. As a result, it has become easier to assess lesions in the laryngopharyngeal region. The recent incorporation of a working channel into digital transnasal video-endoscopes facilitates diagnostic

Electronic supplementary material The online version of this article (https://doi.org/10.1007/s00405-019-05617-z) contains supplementary material, which is available to authorized users.

Anouk S. Schimberg

Anouk.Schimberg@ radboudumc.nl

1 Department of Otorhinolaryngology and Head and Neck Surgery, Radboud University Medical Center, Postbus 9101, 6500 HB Nijmegen, The Netherlands

2 Center for Health Services Research, Larner College of Medicine, University of Vermont, Burlington, USA and treatment-related procedures. The transnasal approach used during flexible endoscopy results in more surgical control and better patient tolerability than traditional transoral techniques [1]. By eliminating the need for general anesthesia, possible adverse events associated with general anesthesia are averted and the diagnostic and therapeutic phases are accelerated [2].

Over the past 2 decades, several reviews have been conducted on the development of procedures in the office [1, 3-7]. Office-based (OB) procedures such as vocal fold injection (VFI), transnasal flexible laser surgery (TNFLS) [8], flexible endoscopic laryngopharyngeal biopsies (FEB), and transnasal esophagoscopy (TNE) were demonstrated to be feasible, safe and effective [3, 6]. Transnasal esophageal balloon dilation (TNE-BD) has emerged more recently and is a safe and tolerable procedure as well [3]. However, these techniques are not yet widely implemented. A possible explanation might be the financial investment in equipment that is required before the $\mathrm{OB}$ procedures can be performed. Furthermore, inadequate reimbursement has been suggested as a principal barrier to the widespread adoption of $\mathrm{OB}$ 
laryngopharyngeal procedures by several authors, since they may not cover all costs [9-11].

Reimbursement is largely dependent on price negotiations between insurer and provider or hospital, as well as the combined clinical and economic value of the treatment. Therefore, it is important to get a better understanding of cost savings from OR-based laryngopharyngeal procedures to OB procedures, to advice decision-makers regarding adequate reimbursement levels. Even though the actual costs associated with the implementation and practice of OB surgery are context-specific, there is growing evidence to support that OB procedures can be performed at lower costs. This study aims to clarify these cost differences by presenting a systematic review of the relevant literature comparing the costs of laryngopharyngeal surgery performed in the office and the OR.

\section{Methods}

A literature search was conducted in three electronic databases (i.e., PubMed, EMBASE and Cochrane Library) in December 2017, and updated in June 2019. A research protocol was developed prior to the start of the review, which was published on the PROSPERO website on May 1st, 2018 [12]. Keywords for the search query included "pharynx", "larynx", combined with "ambulatory surgical procedures" or "surgical procedures", combined with "costs". A variety of synonyms of these keywords was included in the query (Appendix 1). The aim was to identify all studies that reported on costs of laryngopharyngeal procedures that could either be performed in an OB setting under topical anesthesia, or in an OR setting under general anesthesia (GA). Exclusion criteria were studies not aimed at laryngopharyngeal surgery, not reporting on procedures that could be performed both office-based under topical anesthesia or in the OR under GA, not reporting on a cost-analysis, or not available in English or Dutch. Furthermore, review articles, conference abstracts and animal studies were excluded.

First, duplicate references were removed from the search results (Fig. 1). Two authors (AS and DW) independently assessed articles on their eligibility. Full texts were retrieved and screened if an article was potentially eligible. In case of disagreement between the two assessors, a third author (GB) was consulted and consensus was reached. Data extraction included the following: author, year of publication, country, journal, number of financially analyzed cases, study design, intervention, pathology of studied subjects, perspective of financial analysis, sources and types of financial data, time frame in which financial data were collected, costs items included in financial analyses, currency and study outcomes.

In any analysis of comparative costs of alternative treatments, study outcomes must be an accurate reflection of the

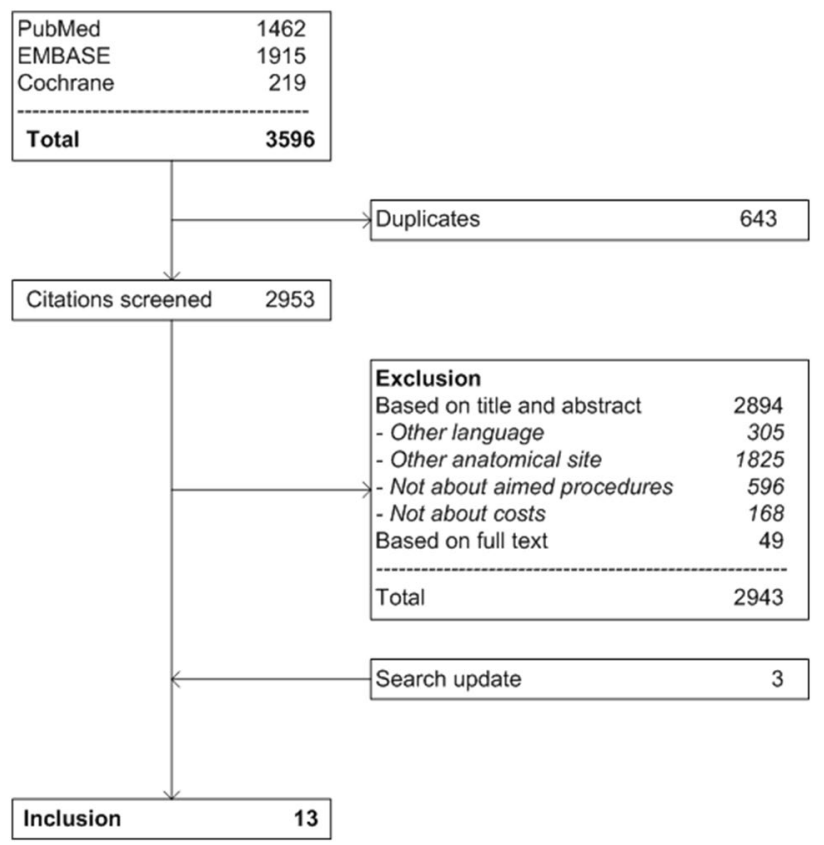

Fig. 1 Flow chart of study selection

economic comparison. Some studies in the past decades, particularly those performed in the United States, have focused on patient bills (charges) as a proxy for costs, but it is important to make a distinction between the economic cost, accounting cost, and charges to the patient, and actual resource consumption [13]. Charges are the individual list prices a hospital must set, usually for administrative purposes, which do not relate to the payments hospitals actually receive. Payments that hospitals receive are based on negotiations between the hospital or provider and the payer (private insurance or government scheme). Payments are not always a direct reflection of actual costs either, they are based on price agreements and negotiated discounts, reflected in claims data. Costs consist of overhead costs for the hospital, the allowance for differential timing of costs, and the role and estimation of productivity costs [14]. In studies in the US, these are usually divided into facility costs and physician costs. Charges usually do not include physician costs.

Many studies use methods to adjust market prices or hospital charges, most often cost-to-charge ratios. But the way the ratios are being calculated differs widely, including converting hospital charges to cost by use of hospital-level cost-to-charge ratios [15] or department-specific ratios [16]. An important conclusion from that literature is that, while there are significant differences in the magnitude of the estimates obtained by these different methods, the method used to estimate costs did not affect the main results of the economic comparison [14]. Therefore, we chose a similar method for our economic comparison of the selected studies, 
where we classified the outcomes into: (1) hospital costs, if possible divided into subcategories of materials, equipment (costs for purchase, depreciation, sterilization, and maintenance), facility costs, supporting departments and overhead costs; (2) hospital charges, and (3) physician costs or fees. As mentioned, the proportion of charges that is covered by the insurer depends on agreements and contracts between the hospital and third party payers. Actual hospital costs are thus a better approach of the value of the provided service than charges, and therefore the focus of this review was set on these costs. Physician fees can also be subject to local agreements, therefore this category was separately evaluated.

In case important information was missing in the included articles (e.g., an itemized list of costs or charges), the corresponding author was consulted. In some cases, additional data were sent and used in our cost calculations. Therefore, the amounts displayed in this review can differ from the amounts displayed by the original articles. Additionally, some authors indicated that costs were an equivalent of charges in their health care system. Hence, charges displayed in those studies were documented as costs, as those amounts still reflected the (approximate) actual value of the provided service.

To eliminate currency variability and thereby improve the comparability of study outcomes, costs were converted into Euros (IMF data set, reference country the Netherlands, reference year 2019) using the CCEMG-EPPI-Centre Cost Converter. This converter accounted for currency conversion as well as inflation factors [17]. When a range of years was described in the included article, the median was used for cost conversion. In case the time frame in which the costs were made was not stated, the year of publication was used for the cost conversion. In addition, relative cost differences (\%) between office-based and operating room-procedures were calculated per study by dividing the costs of the OBprocedure by the costs of the OR-procedure.

Two authors (AS and DW) independently assessed the methodological quality of the included references. The BMJ checklist for economical evaluations [18] and the CHEC (Consensus Health Economic Criteria) [19] was adapted and used for the assessment. The quality criteria that were addressed can be found in Table 1 .

\section{Results}

\section{Search results and study selection}

The search strategy yielded a total of 2953 unique articles (Fig. 1). After excluding 2894 articles based on title and abstract, 59 articles were considered potentially eligible and full text was retrieved. From this selection, another 49 articles were excluded because inclusion criteria were not met.
The search update yielded three additional articles suitable for inclusion [20-22]. In total, 13 articles were included [911, 20-29].

\section{Data extraction}

Table 2 shows a summary of the extracted data from the included articles. All included articles concerned retrospective reviews. All articles used financial data based on actual cases, except for the studies of Castillo Farías et al. [25] and Schutte et al. [21], who estimated costs based on costs of materials, facilities and personnel required to perform these procedures in general. Hospital costs were discussed in seven studies [9, 10, 21, 22, 25-27]; hospital charges in eight studies [9, 11, 20, 23, 24, 27-29]. All included studies reported on costs from a hospital's perspective. The time frame in which financial data were collected ranged from 1995 to 2018. In the studies of Hillel et al. [27] and Chandran et al. [26], the analyzed costs were about awake surgery performed in the (in-hospital) endoscopy suite or instead of the office. The included parameters for costs or charges differed among studies. For example, some studies explicitly described that purchase costs, write-off and maintenance of technical equipment, such as for video-endoscopes with working channel, were incorporated in the cost-analysis [9, 20-22, 26]. Two studies did not specify the items included in the costs analysis [23, 24]. One study did not include physician fees in the cost-analysis, but focused rather on facility costs [20]. Table 3 demonstrates the number of studies that addressed the costs of the different procedures.

\section{Quality assessment}

The quality assessment (Table 1) illustrates that none of the included articles implemented a formal cost-analysis, as can be understood from the absence of sensitivity analyses, reports on productivity changes, and discounting. In many studies the included costs were lacking essential items, such as costs for equipment and overhead costs. As a result most estimates will include measurement error, varying in both magnitude and direction.

\section{Hospital costs}

All included studies reported that hospital costs for OB procedures were reduced compared to similar procedures performed in the OR. The relative reduction in hospital costs varied from 22\% [27] to 46\% [27] (Fig. 2). Because hospital costs were not always presented separately from physician fees, total hospital costs including physician fees are also depicted. The relative reduction in total hospital costs including physician fees ranged from $27 \%$ [27] to $95 \%$ [25] per procedure. Specifically, for VFI procedures, total costs 
2966

European Archives of Oto-Rhino-Laryngology (2019) 276:2963-2973

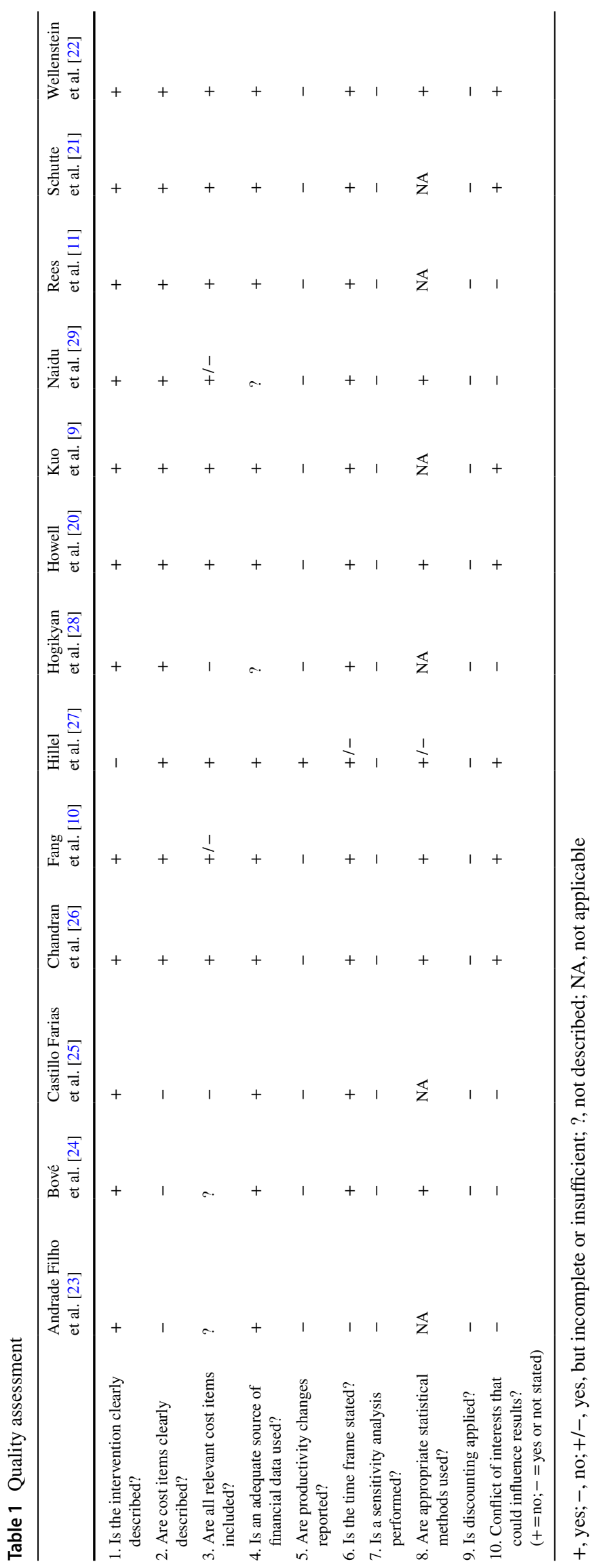

Springer 


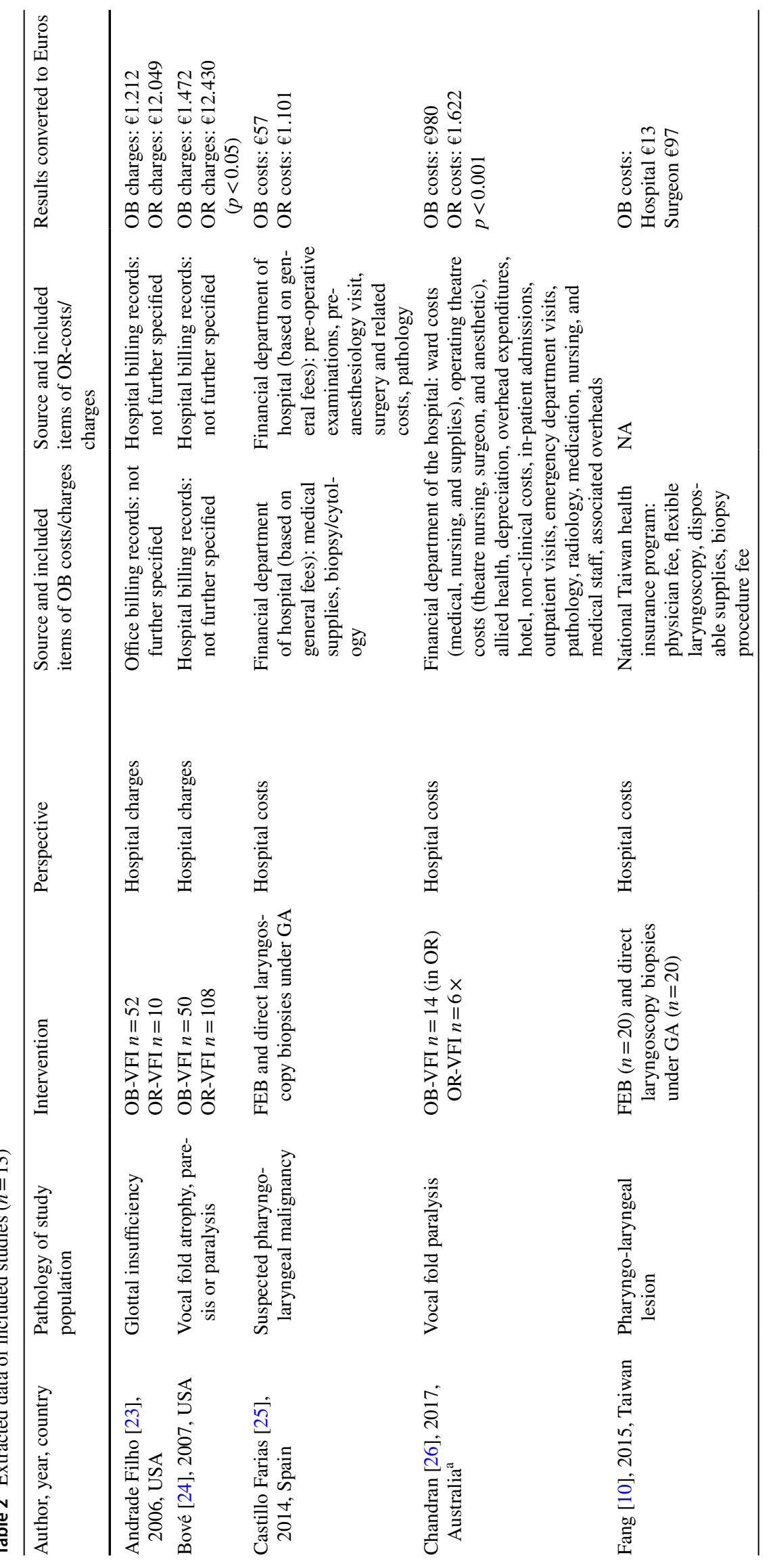




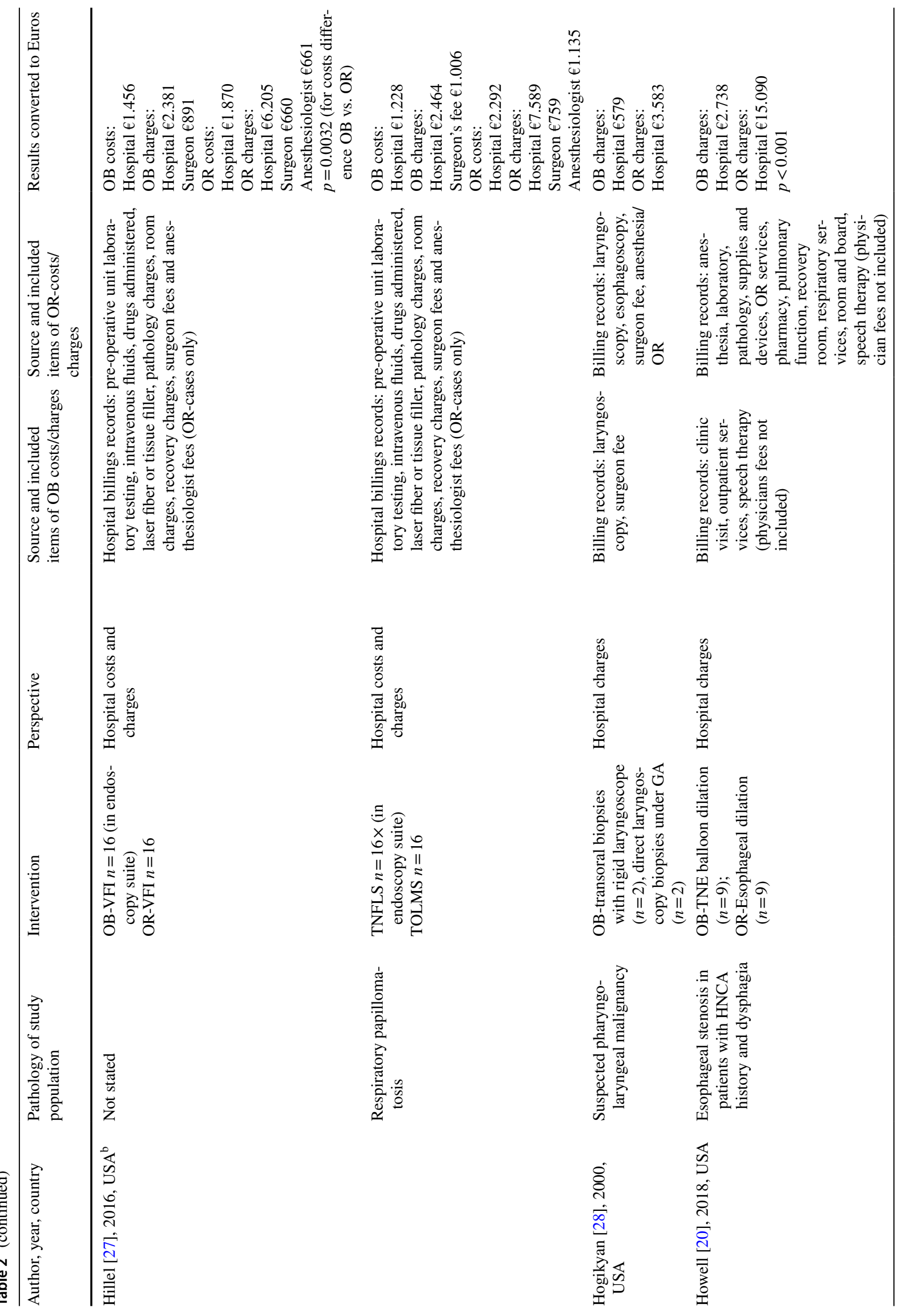




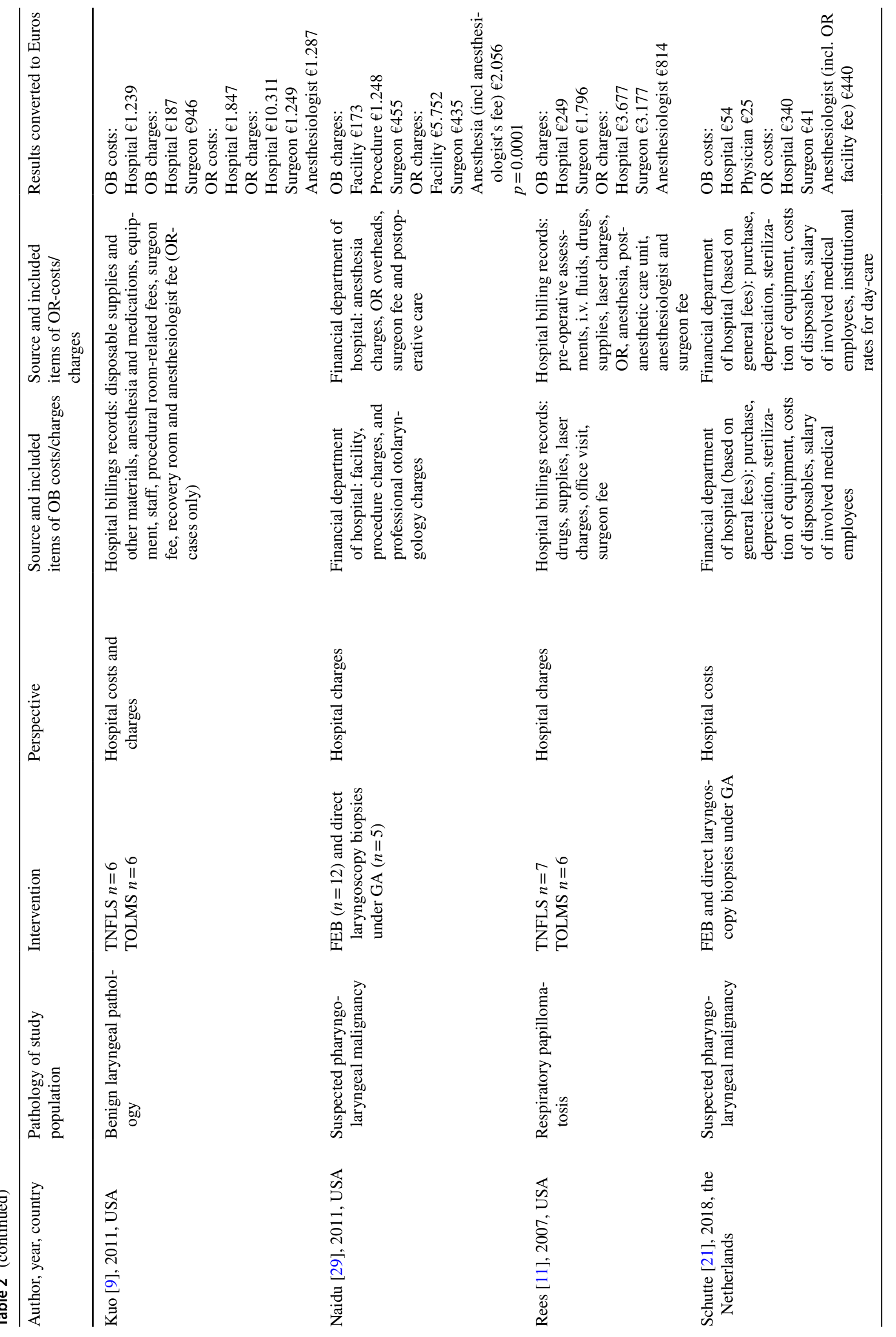




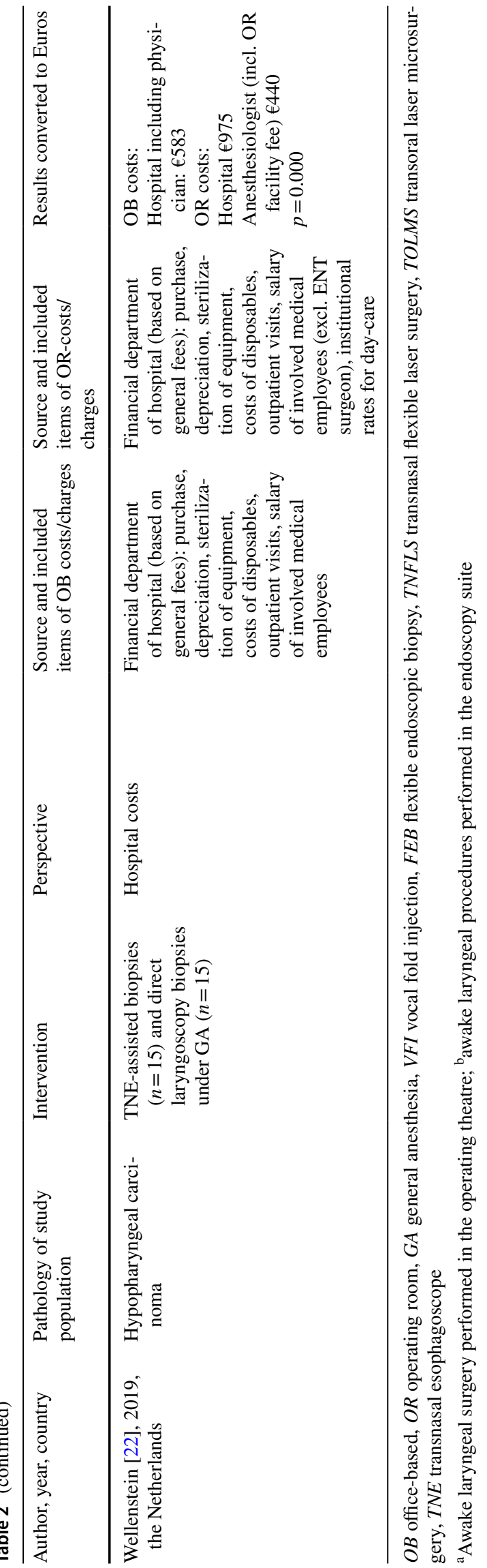

ranged from $€ 980$ [26] to $€ 2.347$ [27] when performed in an OB setting, and from $€ 1.622$ [26] to $€ 3.191$ [27] when performed in the OR. Costs of OB TNFLS ranged from $€ 2.185$ [9] to $€ 2.234$ [27], and for OR-performed TNFLS costs ranged from $€ 4.186$ [27] to $€ 4.383$ [9]. Costs of FEB ranged from $€ 57$ [25] to $€ 110$ [10], whereas costs for biopsies obtained under GA varied between $€ 822$ [21] and $€ 1.101$ [25]. Costs for the diagnostic trajectory in hypopharyngeal carcinoma were $€ 583$ when performing TNE-assisted biopsies compared to $€ 1415$ when performing biopsies under general anesthesia [22].

\section{Hospital charges}

All included studies revealed that hospital charges for OB procedures were reduced compared to similar procedures performed in the OR. The relative reduction in hospital charges varied from 62\% [27] to 98\% [9] (Fig. 3). The relative reduction in hospital charges including physician fees ranged from $73 \%$ [11] to 89\% [23]. By comparing Figs. 2 and 3, the large differences in costs and charges can be deducted. Additionally, a substantial variation existed within hospital charges, especially in OR-performed procedures (€3.677 [11]-€15.080 [20]).

\section{Physician fees}

Except for charges reported in one study [11], otorhinolaryngologist fees for OB and OR-performed procedures were comparable (Fig. 4). Still, a wide variation in physician fees existed, i.e., $€ 25$ [21]- $€ 1.796$ [11] per OB procedure and $€ 41$ [21]-€3.179 [11] per OR procedure. As anesthesiologists are not involved in OB procedures, total physician charges in OB procedures are lower than OR-performed procedures.

\section{Discussion}

This study identified and evaluated differences in health care costs between the OB and OR-performed laryngopharyngeal surgery. By reviewing the relevant literature between 1995 and 2019, it was demonstrated that significant cost savings can be realized by shifting laryngopharyngeal procedures from the OR to the outpatient clinic.

In this review, clear distinctions were made between costs and charges, because costs do not correspond with charges. It is important to consider that health care providers in certain countries tend to inflate charges for their services, as third party payers cover only small proportions of the billed amounts [30]. This phenomenon also follows from our results, in which hospital charges are much higher than the actual costs incurred by the hospital in providing the service. On the other hand, cost analyses are often incomplete 
Table 3 The number of included studies addressing costs of several types of officebased surgery

$$
\text { Procedure }
$$

Number of studies addressing costs of this procedure

Vocal fold injection (VFI)

$4[4,23,26,27]$

Transnasal flexible laser surgery (TNFLS)

$3[1,7,9]$

Flexible endoscopic (laryngopharyngeal) biopsies (FEB)

Transnasal esophageal balloon dilation (TNE-BD)

$5[1,5,8-10]$

$1[20]$

Transnasal esophagoscope-assisted biopsies (TNE-B)
$1[2]$

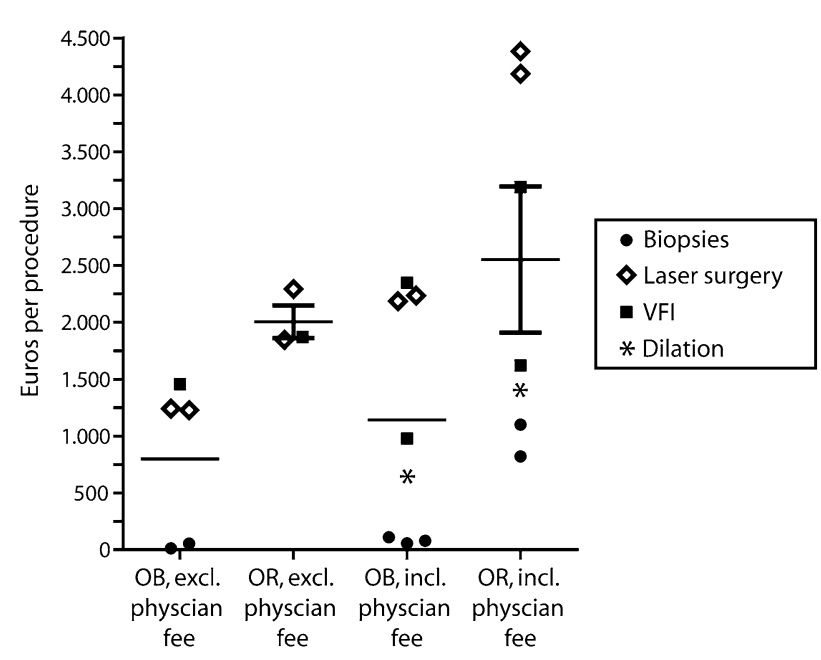

Fig. 2 Hospital costs (with and without physician fees) for officebased and OR-performed procedures in Euros per procedure

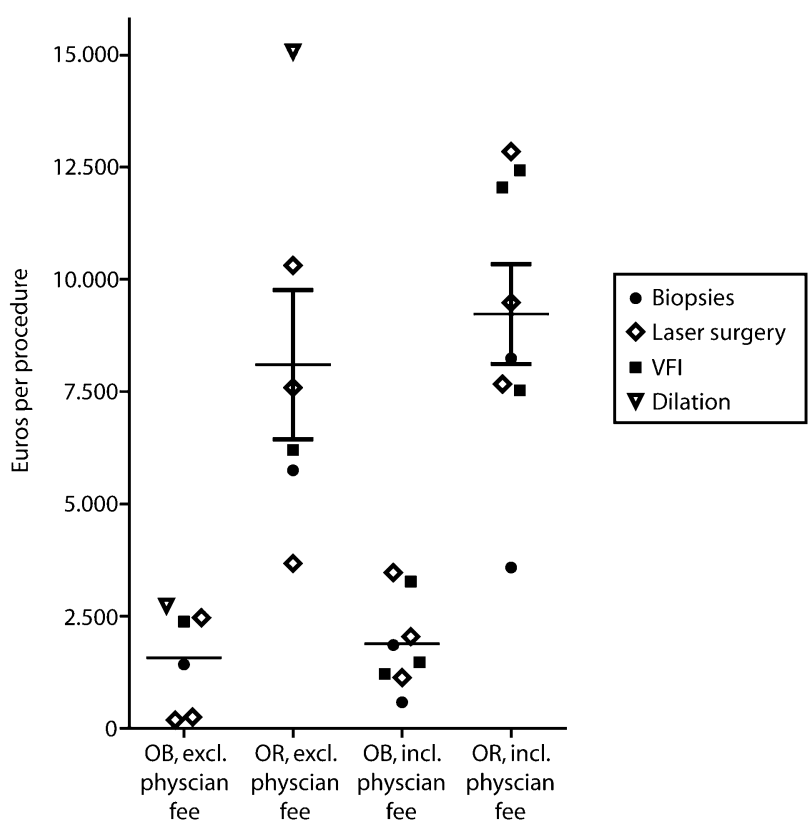

Fig. 3 Hospital charges (with and without physician fees) for officebased and OR-performed procedures in Euros per procedure

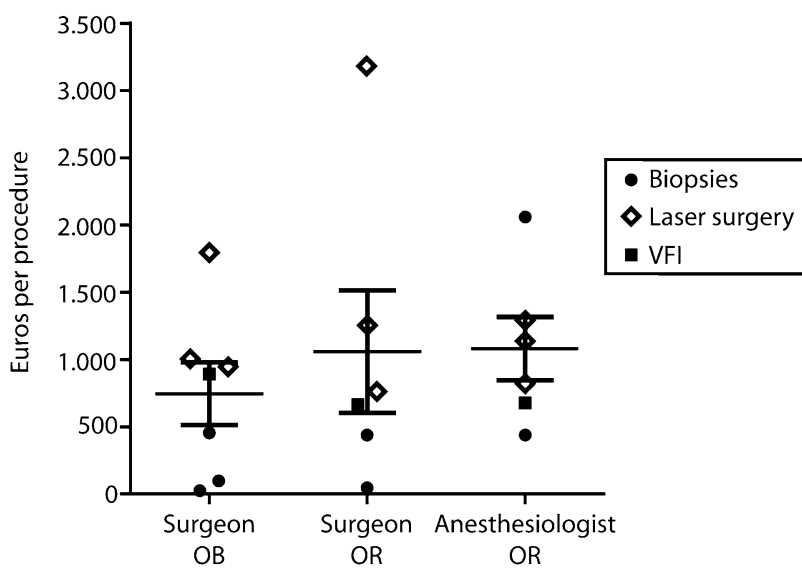

Fig. 4 Physician fees for office-based and OR-performed procedures in Euros per procedure

as important cost items are not always included, while charges obtained from billing records assumedly consist of full charges. There is also variation in cost-to-charge ratios within one hospital or health system which is not always transparent.

This review revealed that procedures under topical anesthesia resulted in hospital cost reductions of up to $95 \%$ per procedure compared to similar procedures under GA. However, the total costs per procedure varied widely between studies. Several reasons for variations in cost outcomes can be outlined. First, the investigated procedures require different equipment or materials. For example, flexible endoscopic laser surgery requires an expensive laser fiber, while flexible biopsy forceps for FEB are significantly less costly. In addition, the cost items that were involved in the analyses differed between the included studies. Differences existed in whether pre-operative general examinations, purchase and use of expensive equipment, or overhead costs were incorporated. Costs for learning these new surgical techniques (e.g., costs for courses and prolonged surgery duration) were not considered in any of the studies. Third, two of the included studies described that awake surgery was performed in the endoscopy suite [27] or in the OR [26], instead of the (nonfacility based) office, to bypass reimbursement problems for 
in-office procedures. Both reports described the least cost reductions among the included articles. Endoscopy suites or ORs, even though no anesthesiologist is involved during the procedure, are associated with higher facility charges than the outpatient office. For practitioners who want to start performing OB laryngopharyngeal surgery, but find safety issues prohibitive, using the endoscopy suite or can be helpful as these settings usually provide adequate materials and staff.

Possible predictors of costs per procedure were analyzed by one study. Chandran et al. described that time spent in the operating theatre was a significant predictor for total costs, but when time was excluded from the multiple linear regression model, type of anesthesia emerged as an independent predictor of total costs [26]. These findings reveal that topical anesthesia is directly linked with reduced costs.

The opacity of financial data in current health care systems around the world is challenging in this type of research and leads to limitations. The costs of delivering health care are obscured in layers of jargon and complex accounting [30]. Hence, it is difficult to gain full insight in the financial aspects of provided health care services. Additionally, differences between countries in organization and financing of health care, and diverging methodology among the included studies lead to difficulties in comparability of the study outcomes. Even within countries, differences between health care organizations can lead to external validity and generalizability issues. Taking this into account, we improved comparability as much as possible by converting financial data of the included studies into Euros and correcting for inflation over years. Still, due to the diverging methodology, statistical (meta-)analysis was not appropriate to perform in this review.

There is an opportunity for cost-effectiveness studies comparing laryngopharyngeal surgery in the office to transoral laryngopharyngeal surgery under general anesthesia, as costs from societal or patient perspective are not yet available. Taking into account the reduced sedative effect when topical anesthesia is used instead of general anesthesia, allowing patients to return to work even the same day as the procedure, costs from patients' perspectives can be significantly diminished. Based on our findings, indications exist that performing laryngopharyngeal surgery in the office under topical anesthesia instead of the OR under GA results in significant costs savings for the hospital and third party payer. Other fields of medicine have also shown cost reductions in shifting surgical interventions to the office [31-34]. To gain full understanding of costs involved in these procedures, broad multi-center cost-effectiveness studies are necessary.

In conclusion, the current review demonstrates that shifting laryngopharyngeal procedures from the OR to the office results in apparent economic benefits. From a physician's point of view, deciding whether to start performing officebased procedures will not only depend on costs, but also on training of the surgeon and other involved staff and availability of materials, instruments and facilities. The results of this review contribute to a better understanding of cost savings from shifting OR-based laryngopharyngeal procedures to the office and can reinforce physicians who are planning to make this shift. Furthermore, the results can be used to guide decision-makers regarding adequate reimbursement levels.

\section{Compliance with ethical standards}

Conflict of interest This study was supported by an unrestricted research grant provided by Pentax Medical Europe.

Open Access This article is distributed under the terms of the Creative Commons Attribution 4.0 International License (http://creativeco mmons.org/licenses/by/4.0/), which permits unrestricted use, distribution, and reproduction in any medium, provided you give appropriate credit to the original author(s) and the source, provide a link to the Creative Commons license, and indicate if changes were made.

\section{References}

1. Rosen CA, Amin MR, Sulica L, Simpson CB, Merati AL, Courey MS et al (2009) Advances in office-based diagnosis and treatment in laryngology. Laryngoscope 119(Suppl 2):185-212

2. Lee F, Smith KA, Chandarana S, Matthews TW, Bosch JD, Nakoneshny SC et al (2018) An evaluation of in-office flexible fiber-optic biopsies for laryngopharyngeal lesions. J Otolaryngol Head Neck Surg 47(1):31

3. Wellenstein DJ, Schutte HW, Marres HAM, Honings J, Belafsky PC, Postma GN et al (2017) Office-based procedures for diagnosis and treatment of esophageal pathology. Head Neck 39:1910-1919

4. Koufman JA (2007) Introduction to office-based surgery in laryngology. Curr Opin Otolaryngol Head Neck Surg 15:383-386

5. Zeitels SM, Blitzer A, Hillman RE, Anderson RR (2007) Foresight in laryngology and laryngeal surgery: a 2020 vision. Ann Otol Rhinol Laryngol Suppl 198:2-16

6. Wellenstein DJ, Schutte HW, Takes RP, Honings J, Marres HAM, Burns JA et al (2018) Office-based procedures for the diagnosis and treatment of laryngeal pathology. J Voice 32:502-513

7. Motz KM, Hillel AT (2016) Office-based Management of Recurrent Respiratory Papilloma. Curr Otorhinolaryngol Rep 4(2):90-98

8. Remacle M, Arens C, Eldin MB, Campos G, Estomba CC, Dulguerov $P$ et al (2017) Laser-assisted surgery of the upper aerodigestive tract: a clarification of nomenclature. A consensus statement of the European Laryngological Society. Eur Arch Otorhinolaryngol. 274(10):3723-3727

9. Kuo CY, Halum SL (2012) Office-based laser surgery of the larynx: cost-effective treatment at the office's expense. Otolaryngol Head Neck Surg 146:769-773

10. Fang TJ, Li HY, Liao CT, Chiang HC, Chen IH (2015) Officebased narrow band imaging-guided flexible laryngoscopy tissue sampling: a cost-effectiveness analysis evaluating its impact on Taiwanese health insurance program. J Formos Med Assoc 114:633-638 
11. Rees CJ, Postma GN, Koufman JA (2007) Cost savings of unsedated office-based laser surgery for laryngeal papillomas. Ann Otol Rhinol Laryngol 116(1):45-48

12. PROSPERO International prospective register of systematic reviews. Registration ID: CRD42018086890. https://www.crd. york.ac.uk/prospero/. Accessed 1 Sept 2019

13. Finkler SA (1982) The distinction between cost and charges. Ann Intern Med 96(1):102-109

14. Drummond MFSM, Claxton K, Stoddart GL, Torrance GW (2015) Methods for the economic evaluation of health care programmes, 4th edn. Oxford University Press, Oxford

15. Taira DA, Seto TB, Siegrist R, Cosgrove R, Berezin R, Cohen DJ (2003) Comparison of analytic approaches for the economic evaluation of new technologies alongside multicenter clinical trials. Am Heart J 145(3):452-458

16. Cohen DJ, Breall JA, Ho KK, Weintraub RM, Kuntz RE, Weinstein MC et al (1993) Economics of elective coronary revascularization. Comparison of costs and charges for conventional angioplasty, directional atherectomy, stenting and bypass surgery. J Am Coll Cardiol. 22:1052-1059

17. CCEMG-EPPI-Centre Cost Converter. https://eppi.ioe.ac.uk/costc onversion/default.aspx. Accessed 12 June 2019

18. Drummond MF, Jefferson TO (1996) Guidelines for authors and peer reviewers of economic submissions to the BMJ. The BMJ Economic Evaluation Working Party. BMJ 313(7052):275-283

19. Evers S, Goossens M, de Vet H, van Tulder M, Ament A (2005) Criteria list for assessment of methodological quality of economic evaluations: consensus on Health Economic Criteria. Int J Technol Assess Health Care 21:240-245

20. Howell RJ, Schopper MA, Giliberto JP, Collar RM, Khosla SM (2018) Office-based esophageal dilation in head and neck cancer: safety, feasibility, and cost analysis. Laryngoscope 128:2261-2267

21. Schutte HWTR, Slootweg PJ, Arts MJPA, Honings J, van den Hoogen FJA, Marres HAM, van den Broek GB (2018) Digital video laryngoscopy and flexible endoscopic biopsies as an alternative diagnostic work-up in laryngopharyngeal cancer; a prospective clinical study. Ann Otol Rhinol Laryngol. 127:770-776

22. Wellenstein DJ, Honings J, Schutte HW, Herruer JM, van den Hoogen FJA, Marres HAM et al (2019) Cost analysis of officebased transnasal esophagoscopy. Eur Arch Otorhinolaryngol 276:1457-1463

23. Andrade Filho PA, Carrau RL, Buckmire RA (2006) Safety and cost-effectiveness of intra-office flexible videolaryngoscopy with transoral vocal fold injection in dysphagic patients. Am J Otolaryngol 27:319-322
24. Bové MJ, Jabbour N, Krishna P, Flaherty K, Saul M, Wunar R et al (2007) Operating room versus office-based injection laryngoplasty: a comparative analysis of reimbursement. Laryngoscope 117:226-230

25. Castillo Farias F, Cobeta I, Souviron R, Barbera R, Mora E, Benito A et al (2015) In-office cup biopsy and laryngeal cytology versus operating room biopsy for the diagnosis of pharyngolaryngeal tumors: efficacy and cost-effectiveness. Head Neck 37:1483-1487

26. Chandran D, Woods CM, Schar M, Ma N, Ooi EH, Athanasiadis $\mathrm{T}$ (2018) Cost analysis of injection laryngoplasty performed under local anaesthesia versus general anaesthesia: an Australian perspective. J Laryngol Otol 132:168-172

27. Hillel AT, Ochsner MC, Johns MM 3rd, Klein AM (2016) A cost and time analysis of laryngology procedures in the endoscopy suite versus the operating room. Laryngoscope 126:1385-1389

28. Hogikyan ND, Pynnonen M (2000) Indirect laryngeal surgery in the clinical voice laboratory: the renewal of a lost art. Ear Nose Throat J 79:350-361

29. Naidu H, Noordzij JP, Samim A, Jalisi S, Grillone GA (2012) Comparison of efficacy, safety, and cost-effectiveness of in-office cup forcep biopsies versus operating room biopsies for laryngopharyngeal tumors. J Voice 26(5):604-606

30. Arora VMC, Shah N (2015) The challenge of understanding health care costs and charges. AMA J Ethics 17:1046-1052

31. Gill BC, Ulchaker JC (2018) Costs of managing benign prostatic hyperplasia in the office and operating room. Curr Urol Rep 19(9):72

32. Alom M, Ziegelmann M, Savage J, Miest T, Kohler TS, Trost L (2017) Office-based andrology and male infertility procedures-a cost-effective alternative. Transl Androl Urol 6:761-772

33. Boffeli TJ, Abben KW, Hyllengren SB (2014) In-office distal Symes lesser toe amputation: a safe, reliable, and cost-effective treatment of diabetes-related tip of toe ulcers complicated by osteomyelitis. J Foot Ankle Surg 53:720-726

34. Peacock LM, Thomassee ME, Williams VL, Young AE (2015) Transition to office-based obstetric and gynecologic procedures: safety, technical, and financial considerations. Clin Obstet Gynecol 58:418-433

Publisher's Note Springer Nature remains neutral with regard to jurisdictional claims in published maps and institutional affiliations. 